\title{
TRUTH OR CONSEQUENCES: An Analysis of Vaporware and New Product Announcements
}

\author{
Barry L. Bayus \\ University of North Carolina at Chapel Hill \\ Sanjay Jain \\ Purdue University \\ Ambar G. Rao \\ Washington University at St. Louis
}

forthcoming, Journal of Marketing Research

February 1999

Revised June 1999

Revised December 1999

Revised March 2000

We thank Ganesh Iyer and the anonymous reviewers (particularly Reviewer 1) for their comments on an earlier draft of this paper. The authors contributed equally to this paper and are listed in alphabetical order for convenience.

Address all correspondence to: Barry L. Bayus, Kenan-Flagler Business School, University of North Carolina, CB3490, Chapel Hill, NC 27599, (919) 962-3210; e-mail: Barry_Bayus@UNC.edu 


\title{
TRUTH OR CONSEQUENCES: An Analysis of Vaporware and New Product Announcements
}

\begin{abstract}
$\underline{\text { ABSTRACT }}$
The software industry practice of announcing new products well in advance of actual market availability has led to allegations that firms are intentionally engaging in vaporware. The possible predatory and anti-competitive implications of this behavior recently surfaced in the antitrust case United States $v$. Microsoft Corporation. Taking the perspective that a new product announcement is a strategic signal between firms, we consider the possibility that intentional vaporware is a way to dissuade competitors from developing their own competing new products. An examination of empirical data for the software industry suggests that some firms may use vaporware in a strategic manner. We then formulate and analyze the preannouncement and introduction timing decisions in a game theoretic model of two competing firms. We find that vaporware can be a way for a dominant firm to signal its product development costs, and that intentional vaporware can deter entry. We also show that there is a curvilinear relationship between development costs and announcement accuracy, i.e., firms with high or very low product development costs make accurate product announcements, while firms with intermediate product development costs intentionally engage in vaporware. Empirical support for these theoretical results is also found in the software industry data. Finally, we discuss the beneficial and harmful consequences of vaporware, and the associated implications.
\end{abstract}


vaporware $n$. (1) a product that the vendor keeps promising is about to arrive 'real soon now,' but it goes so long past its shipment date that no one believes it will ever really ship (Jargon: An Informal Dictionary of Computer Terms by R. Williams and S. Cummings, 1993); (2) slang for announced software that may never materialize (Computer Dictionary by D. Spencer, 1992); (3) a term used sarcastically for promised software that misses its announced release date, usually by a considerable length of time (Microsoft Press Computer Dictionary 1991).

\section{INTRODUCTION}

Many firms find it beneficial to communicate their development activities to internal and external audiences in advance of a new product introduction (e.g., Wind and Mahajan 1987; Rabino and Moore 1989; Lilly and Walters 1997). In the software industry for example, preannouncing the future availability of new products is widely practiced (e.g., Singh 1997). Given this pervasive activity of firms, industry pundits have coined the term vaporware $e_{\text {to describe products that miss }}$ their previously announced release date.

Due to the various uncertainties in any new product development process, some vaporware is certainly unintentional. At the same time however, some industry participants allege that certain firms intentionally engage in vaporware to gain a competitive advantage. Thus, it should not be too surprising that the practice of vaporware has recently been in numerous headlines (e.g., Jenkins

\footnotetext{
${ }^{1}$ Actually, the term "vaporware" has been used in the computer industry for several years. As a tribute to its pervasiveness, the twentieth anniversary issue of Byte (September 1995) published a list of famous vaporware products. The term arose when Ann Winblad, a former girlfriend of Bill Gates and now a San Francisco area venture capitalist, visited Microsoft in 1982 demanding to know whether it was really planning to develop a piece of Unix software for her Minneapolis company. Getting nowhere with executives, she asked Microsoft engineers John Ulett and Mark Ursino, who used the term to indicate that the project had run out of steam (Flynn 1995). Later, the term came to have broader connotations (Dyson 1987). Infoworld also popularized this term when its editor, Stewart Alsop, presented Bill Gates with the Golden Vaporware award in November 1985 at the Alexic Hotel in Las Vegas (with the speakers blaring “To Dream the Impossible Dream") to celebrate Microsoft's introduction of its first version of Windows (Ichbiah 1993; Garud 1997).
} 
1988; Johnston 1995; Johnston and Betts 1995; Wall Street Journal 1996; Singh 1997) and has been the subject of government scrutiny (e.g., Yoder 1995; U.S. Department of Justice 1995; Black and Wylie 1997)2].

Despite the importance of this topic, the published literature is silent on the possible incentives for a firm to intentionally engage in vaporware. In fact, the few research papers on this topic conclude that firms have no incentives to lie and thus, intentional vaporware does not exist (e.g., Farrell and Saloner 1986; Levy 1997). Unfortunately, this conclusion rings hollow since it lacks face validity given actual marketplace observations of firm behaviors (e.g., Prentice 1996; Orrison 1997). In addition, securities fraud lawsuits involving vaporware have been successful, e.g., the mean settlement in securities class action lawsuits between 1989-1994 for the dissemination of misleading information on products under development was $\$ 7.2$ million, with mean damages assessed at \$47.1 million (Carleton, Weisbach, and Weiss 1996) ${ }^{\text {B }}$. Consequently, the purpose of this paper is to offer one possible explanation for this phenomenon that is in agreement with observed industry practice, i.e., some firms seem to intentionally engage in vaporware while others do not. Specifically, we show that intentional vaporware can be used to deter entry.

Among its possible functions, preannouncing behavior by a firm can be used to: (1) tell potential competitors that it is working on a new product so that the competitors can back off, (2) signal to potential competitors that it is farther along in product development than they, and hence the competitors should back off, and (3) in case it has already been beaten to market by a competitor,

\footnotetext{
${ }^{2}$ Since there are possible predatory and anti-competitive implications associated with false product announcements, there might be a violation of antitrust laws (i.e., there is a potential violation of the Sherman Act which carries a treble damage judgement; see Heil and Langvardt 1994; Dratler 1996; Prentice 1996).
} 
tell consumers to wait for its product so that the acceptance of the competitor's product will be delayed. See Eliashberg and Robertson (1988) and Lilly and Walters (1997) for other uses of preannouncements by firms. Unlike the existing research on this topic (e.g., Farrell and Saloner 1986; Eliashberg and Robertson 1988; Lilly and Walters 1997; Levy 1997), the focus of this paper is on a firm's use of preannouncements in telling potential competitors about its new product development efforts. Thus, our approach follows the long and rich descriptive and empirical literature, which views product preannouncements as inter-firm signals (e.g., Porter 1980; Chaney, Devinney, and Winer 1991; Robertson, Eliashberg, and Rymon 1995; Koku, Jagpal, and Viswanath 1997, Heil and Robertson 1991). However, our work differs from this literature in that we employ a game theoretic model to formally examine the role of preannouncements in the context of rational firms. Furthermore, in this paper we are concerned with the phenomenon of intentional vaporware (i.e., intentionally false preannouncements). We consider a situation in which competitors simultaneously decide whether (and when) to introduce a new product. Our game theoretic results show that rational firms may want to practice intentional vaporware. This is in sharp contrast to the prevailing thought that firms have no incentives to engage in intentional vaporware.

From a methodological perspective our paper is related to the game theoretic literature on signaling. This research has examined various mechanisms by which a firm can provide information to either consumers or competitors about a latent variable that has some relevance for decisions. Researchers have considered various signaling tools such as pricing, advertising, warranty policies, money back guarantees to signal latent variables like product quality (e.g., Kihlstrom and Riordan

\footnotetext{
${ }^{3}$ In another notable vaporware lawsuit involving the Lisa computer and Twiggy disk drive, Apple Computer was hit with a jury verdict of $\$ 100$ million and was fortunate to later settle the case out of court for only $\$ 16$ million. See Prentice and Langmore (1994) for a discussion of this case and others.
} 
1984; Lutz 1989; Bagwell and Riordan 1991; Moorthy and Srinivasan 1995), network externalities (e.g., Padmanabhan, Rajiv, and Srinivasan 1997), and marginal costs (e.g., Milgrom and Roberts 1982; Srinivasan 1991). An important subset of this literature specifically deals with entry deterrence (e.g., Milgrom and Roberts 1982; Srinivasan 1991; Balachander and Srinivasan 1994). This research has primarily focused on examining the phenomenon of predatory pricing and limit pricing. For example, Milgrom and Roberts (1982) show that rational firms can use limit pricing in order to deter entry. Our research differs from the extant game theoretic research in two ways. First, our paper formally establishes the possible role of product preannouncements as a signaling device. Specifically, we show that product preannouncements can be used by firms to signal product development costs (which are not marginal costs). This is important since product development costs are a function of a firm's entry time, which is endogenous in our model. Second, we show that preannouncements can be used to deter entry. This is different from the existing models of entry deterrence, which have primarily focused on the role of price in deterring entry

To provide a specific context for our research, in the next section we discuss the role of new product announcement behavior in the personal computer software industry and present some descriptive data on vaporware over the ten-year period between 1985-1995. These data suggest that firms may use vaporware in a strategic manner (i.e., firms miss their announced shipment dates in a non-random fashion). This implies that intentional vaporware may be practiced by some firms.

Then, in Section 3 we formulate and analyze a model that can account for these empirical observations. Consistent with industry usage of the term as well as the usual "definitions," we

\footnotetext{
${ }^{4}$ This focus of prior literature on price as a signaling tool is understandable since these papers were interested in pricing issues: specifically, predatory and limit pricing. It is important to note however, that in the context that we
} 
consider preannouncements to only be concerned with the timing of the future availability of a new product. In contrast to the existing research literature (e.g., Farrell and Saloner 1986; Levy 1997), we do not limit our attention to the situation in which a product announcement is only used in response to a competitive product introduction, and consequently, we do not emphasize the possible role of intentional vaporware in eliminating a rival's first mover advantage. Instead, we study the situation in which: (1) a preannouncement occurs before the market introduction of a new product, (2) preannouncements are used to signal product development cost information between firms, and (3) intentional vaporware occurs when, having used a preannouncement to deter entry, a firm introduces its new product at an optimal time later than originally announced. In our model, preannouncing serves the function of signaling that a firm has low product development costs (possibly as a result of starting its product development earlier than its competitor), and therefore, a competitor should refrain from developing its own competing new product. Thus, the goal of the preannouncement is to provide information that will tell a potential entrant that competition will be unprofitable for it, and therefore it would be better to forego entry and thereby save its development costs. Since there are penalties for false announcements (e.g., potential legal expenses associated with an antitrust investigation, as well as losses in reputation that will negatively affect future sales of the firm), a firm with low product development costs can credibly engage in intentional vaporware to signal to competitors that its development costs are indeed low. The reason the signal works is that it is not profitable for a firm with high product development costs to mimic the announced early entry time. Therefore, a firm with low product development costs successfully deters entry, and can then introduce its product as a monopolist at a later time than originally announced if this is optimal.

study (i.e., new product preannouncements in which both firms may be entrant firms) prices cannot be used to deter 
We also show that firms with very low product development costs can deter entry, but do not need to engage in vaporware.

In Section 4, we revisit the vaporware data from the software industry to obtain empirical evidence supporting our analytical results. We conclude in Section 5 by discussing the beneficial and harmful consequences of vaporware and the associated implications. We also offer some promising directions for future research.

\section{SOME EMPIRICAL OBSERVATIONS}

\subsection{The Software Industry}

Software is one of the largest and fastest growing industries today, with global sales of packaged software over $\$ 100$ billion (Anderson 1996). Competition in the software industry is between large, dominant firms as well as numerous small, entrepreneurial firms. For example, a casual search of computer trade magazines indicates that competition in the spreadsheet market since 1984 has been between large, dominant firms like Microsoft (Excel) and Lotus (1-2-3), as well as numerous smaller firms like Interface Technologies (Farsight), Paperback Software International (VP-Planner), Ontio Computer Products (Ontio 259), Mosaic Software (The Twin), Daybreak (Silk), Indian Ridge Enterprises (THE Spreadsheet), ButtonWare (PC-Calc, a shareware program), and Tidestone Technologies (Formula One, a Java-based program). Informal discussions with industry participants also suggests that the smaller firms often base their new product development efforts around the new product announcements of their more dominant competitors (e.g., smaller firms may decide to "get out of the way" of a larger firm like Microsoft by concentrating their limited development efforts in other markets; see Prentice and Langmore 1994; Prentice 1996).

entry since firms cannot commit to prices in advance of product launch. 
Software development is a complex venture that is laden with uncertainty. Software is a "systems" product that is generally composed of several interacting components or features that are assigned to different programmers or teams of programmers. Although each software component may independently accomplish its designed task, it is very difficult to anticipate how this component will interact with other features in the complete program. Software development is still thought to be largely an art form 5 . Fixing the resulting computer "bugs" and software glitches is thus an important and on-going part of the software development process (e.g., see Cusumano and Selby 1995; Mossberg 1995; Rigdon 1995). Whereas the planning stage in software development can take between 3 and 12 months, development, debugging, and internal/external testing often lasts between 6 and 20 months (Soft-Letter 1991; Cusumano and Selby 1995). Thus, there are often legitimate reasons for delays in software development (Jenkins 1988; van Genuchten 1991; McConnell 1996) At the same time however, there is some evidence that software development is maturing and firms are better able to plan their development efforts (e.g., Cusumano 1991; Carmel and Becker 1995; Cusumano and Selby 1995; Blackburn, Hoedemaker, and van Wassenhove 1996; Iansiti and MacCormack 1997).

In any event, it is very clear that some software ships very close to its announced release date, whereas other software actually ships long after the first announced release date. For example, the announced release date and actual ship date for Lotus Notes was December 1989, whereas the actual

\footnotetext{
${ }^{5}$ For example, it is generally believed that "the best code is still done by small teams of young American coders eating pizza and drinking Coca-Cola” (Dvorak 1993, p. 95).

${ }^{6}$ Of course, not everyone agrees. For example, Eric Dickstein, a lead technical analyst at Continental Grain Corp. of New York, believes that "Microsoft can ship a complete product on time if they choose. They were able turn the entire organization around to get Internet products out the door within a year" (Computerworld, March 17, 1997).
} 
ship date for Microsoft Windows was eighteen months after its announced release date of May 1984. This latter behavior of announcing a new software product well in advance of its market introduction has led to allegations of intentional vaporware. In the software industry, the antitrust implications of vaporware recently surfaced in the case United States v. Microsoft Corporation. In rejecting the Justice Department's proposed settlement with Microsoft, U.S. District Judge Stanley Sporkin repeatedly chastised the government for not questioning Microsoft's new product announcement practices. According to Judge Sporkin, "Vaporware is a practice that is deceitful on its face and everybody in the business community knows it" (Yoder 1995, p. B1). See Lopatka and Page (1995) and Clark and Novak (1995) for a discussion of this investigation.

\subsection{Data and Analysis}

In this section, we empirically explore the vaporware activity of software firms. We assembled information on a sample of new product announcements and introductions in the software industry from P.C. Letter's “Official Vapor List' $\underline{\text {. }}$. To obtain products for this list, the newsletter's editor, Stewart Alsop, solicited nominations from key industry participants (which have included Bill Gates and other prominent CEOs) and used his extensive experience and knowledge of the industry. All products on this list have been announced and are believed to be important and influential products. Information on the date first announced, the announced release date, and the actual ship date were assembled for 123 software products spanning the ten-year period 1985-1995. Frequency distributions for the times between various dates are in Table 1. As indicated in this table, over 50\%

\footnotetext{
${ }^{7}$ We thank P.C. Letter, and particularly Barbara Newton, for making all of the back issues between January 1985 and May 1995 available to us.
} 
of all the software products in this sample were actually shipped within three months of the announced release date (out of the 123 products in our sample there are only six cases, or five percent, in which products were actually introduced before their announced release date). In addition, the time between first announcement and actual shipment is less than nine months for over $75 \%$ of these software products. And, for over $50 \%$ of these software products, the time between first announced and announced release date was less than six months. Thus, if we accept the industry viewpoint that delays of more than three months between the announced release date and actual ship date represent intentional vaporware (e.g., Papows 1992; Foundyller 1993), over half of all the software products in this sample correspond to vaporware that is not intentional. We note that this is consistent with the cross-industry survey results of Eliashberg and Robertson (1988).

[insert Table 1 about here]

Let us define $\mathbf{V}$ to be the time between the announced release date and actual ship date (i.e., announcement accuracy). Note that $\mathbf{V}$ can be negative if the product is introduced prior to its announced date. Now, consider the histogram of $\mathbf{V}$ shown in Figure 1. We note that a symmetric distribution around 0 would suggest that there is no systematic relationship between the announced release dates and the actual ship dates of the firms in our sample (i.e., all vaporware is unintentional). Clearly, this histogram is not symmetric around 0 (the mean of $\mathbf{V}$ is 3.5 months which is significantly different than $0 ; \mathrm{t}=8.18, \mathrm{p}=0.00$ ). One possible explanation for these results is that some firms do

\footnotetext{
${ }^{8}$ For example, the now-defunct industry group called the Software Business Practices Council recommended in 1990 that the time between first announcement and actual availability should be no longer than nine months (Johnston and Betts 1995). Other industry pundits have argued that a 60-day (e.g., Papows 1992) or 90-day (e.g., Foundyller 1993) time between the announced release date and actual availability (i.e., ship time) is tolerable. An industry study also indicates that the median delay for late software product is three months (Soft-Letter 1991).
} 
use vaporware in a strategic manner (i.e., some vaporware is intentional). In addition, for $\mathbf{V}>0$, if all vaporware were unintentional we would expect that $\mathbf{V}$ is positively correlated with how far in advance of the release date announcement is made (i.e., the farther the preannounced date is into the future, the more likely a firm will make an error in accurately forecasting its product introduction time). Empirically however, we find that there is no relationship between $\mathbf{V}$ and how far in advance of the release date the announcement was made (Table 1 , column 1), i.e., $r=0.02 ; \mathrm{p}=0.85$. To further explore this null result, we tested whether this holds when controlling for firm size (i.e., do the possibly different software development processes of large and small firms matter), whether the firm was publicly or privately owned (i.e., do the different incentive structures of public vs. private firms matter), and year in which the product announcement was made (i.e., is there a systematic trend in announcement accuracy over time). Although not reported here, we find that none of these variables are significant in a regression analysis.

[insert Figure 1 about here]

\subsection{Summary}

Our discussion and empirical analysis of new product announcement behavior in the software industry leads to the following three main observations. First, the numerous small, entrepreneurial firms in the software industry frequently base their new product development efforts around the new product announcements of their larger, more dominant competitors. Second, new software development is an inherently uncertain process in which there are often legitimate reasons for delays. Third, in addition to the usual uncertainties in the new product development process, some software firms may intentionally use vaporware in a strategic manner.

\section{A MODEL AND ANALYSIS}


In this section, we formulate and analyze a stylized model of the timing of new product introduction with the possibility of product preannouncements. We consider a new product to include new software titles, as well as upgrades of existing titles. We study the incentives for intentional vaporware by emphasizing the inter-firm signaling aspects, and assume that false announcements have associated penalty costs ${ }^{\natural}$. We consider the possibility that intentional vaporware can be a way to discourage other firms from developing their own products. To make these points as clearly and as simply as possible, we consider a duopoly with one firm as the dominant firm. "Dominance" is incorporated in our model formulation via the strong assumption that followers cannot expect to succeed if they enter later than the dominant firm. We will further assume that firms can choose their product introduction time with certainty. In reality, of course, a firm cannot determine its product introduction time without error and consequently some vaporware is unintentional. Our assumption, however, allows us to focus on the more interesting case of intentional vaporware.

The sequence of decisions in our model is as follows. At time 0, Firm 1 (the dominant firm) preannounces an introduction time $T_{a}$ that is observed by Firm 2. (We argue later that total expected duopoly profits are higher with preannouncements than without.) After the preannouncement, both firms simultaneously decide on a time of entry by maximizing their discounted expected profits over

\footnotetext{
${ }^{9}$ For example, the thirteen year Justice Department's antitrust investigation of IBM cost the company and government an estimated \$200 million only for legal and photocopying costs (Wall Street Journal 1982). By the end of the case, IBM was paying $\$ 5$ million a year just to store the forty-six thousand tons of documents associated with the investigation (Chase 1982). One study estimates that the cost of private antitrust lawsuits to US companies is \$250 million per year (Shughart 1990). In the 1990-1991 period, 300 class action securities fraud suits were filed at an average litigation cost of $\$ 692,000$ per suit (Bowers and Gupta 1994). In total for 1992, class-action defendants paid settlements of approximately $\$ 1.55$ billion, with the average settlement being around $\$ 10.8$ million (Bowers and Gupta 1994). It has also been argued that the reputations of IBM and Wang Laboratories were damaged by not living up their own product announcements (Prentice and Langmore 1994). See also Landis and Rolfe (1985).
} 
time. If Firm $i$ is a monopolist in the market, its expected revenues per period are denoted by $\pi_{i}^{m}$. In line with software industry experiences, we assume that the marginal costs of production are negligible for each firm (e.g., Shapiro and Varian 1998). When Firm $i$ is in the market with the other firm, its expected duopoly revenue flow is denoted by $\pi_{i}^{d}$. We make the usual assumption that $\pi_{i}^{m}>\pi_{i}^{d} \geq 0$. If Firm $i$ decides to enter at time $t$, we define the net present value of its product development costs to be $c_{i}(t)$. Consistent with empirical findings (e.g., see the review in Graves 1989), we also write Firm 1's product development cost function as $c_{1}(t)=\alpha \psi(t)$. The parameter $\alpha \geq 0$ will be used later to model Firm 2's uncertainty about Firm 1's product development costs Finally, we assume that false preannouncements are costly, i.e., if Firm 1 preannounces an introduction time $T_{a}$ and enters at $t>T_{a}$, then it incurs a penalty cost (e.g., see Landis and Rolfe 1985; Shughart 1990; Prentice and Langmore 1994). We model this cost as a function $p\left(t-T_{a}\right)=\beta \xi\left(t-T_{a}\right)$ where $\xi\left(t-T_{a}\right)>0$ for $t>T_{a}$ and 0 otherwise, and $\beta \geq 0$ is a constant.

The following mathematical assumptions ensure the environment discussed above.

Assumption 1: $c_{i}^{\prime}(0)<0, c_{i}^{\prime \prime}(t)>0$ and $\lim _{t \rightarrow \infty} c_{i}^{\prime}(t)>0$ for $i=1,2$.

We note that this assumption is consistent with prior empirical findings that show the relationship between a firm's development costs and its entry time is a U-shaped function (e.g., Mansfield 1971; Brooks 1975; Putnam and Fitzsimmons 1979; Boehm 1981; Graves 1989). The assumption that $\lim _{t \rightarrow \infty} c_{i}^{\prime}(t)>0$ guarantees that each firm has a positive, finite product introduction time absent strategic considerations.

\footnotetext{
${ }^{10}$ We can also admit exogenous market growth effects in the model by including an appropriate term. For example, exponential growth can be incorporated by multiplying $\pi_{i}$ with $\mathrm{e}^{\rho t}$. As long as $\rho$ is less than the discount rate, the analytical results in this section remain unchanged.

${ }^{11}$ The parameter $\alpha$ can also be interpreted as representing how far Firm 1 is along in its development process at the time of its preannouncement. Thus, firms with a low $\alpha$ incur lower costs to introduce a product at any given time than firms with high $\alpha$, since firms with low $\alpha$ have already made substantial progress in developing the product.
} 
Assumption 2: $c_{i}^{\prime \prime}(t)>r e^{-r t} \pi_{i}^{m}$ for $i=1,2$.

This assumption ensures that the profit functions are concave (e.g., see also Reinganum 1981).

Assumption 3: $\pi_{2}^{d} \leq c_{2}\left(t_{2}\right) r e^{r t_{2}} \forall t_{2}$.

This assumption ensures that Firm 2 will not find it profitable to be a follower (since Firm 1 is dominant). We note that this assumption is always satisfied if $\pi_{2}^{d}$ is close to zero. Note that this assumption does not rule out entry by Firm 2 before the dominant firm.

Assumption 4: $\pi_{2}^{m}<-c_{2}^{\prime}(0)$.

This assumption rules out the possibility of immediate entry by Firm 2 .

Assumption 5: $-\left(\pi_{2}^{m}-\pi_{1}^{d}\right) e^{-r t}-\left(c_{2}^{\prime}(t)-c_{1}^{\prime}(t)\right) \leq 0$.

This assumption ensures that Firm 2's optimal entry time $t_{L}^{*}$ is less than Firm 1's entry time $t_{F}^{*}$.

Assumption 6: $\xi^{\prime}(x)>0$ for $x>0, \xi^{\prime \prime}(x)>0$, and $0<\lim _{t \downarrow T_{a}} \xi^{\prime}\left(t-T_{a}\right)<\infty$.

This assumption ensures that penalty function is an increasing convex function of the difference between the actual entry time and the announced time, and also ensures that penalty costs are not so large that a firm will never find false preannouncements to be profitable.

Finally, we note that all of our analytical results in this section extend to the situation when either firm (or both) already has a product in the market, i.e., either firm (or both) may be considering an upgrade to one of its existing products. Although the details are not provided here (but are available upon request), we only need a model structure with two firms, one of which is dominant, and assumptions similar to those in Reinganum $(1981)^{\underline{L}}$.

Now, we can write the firms' profit functions for various entry decisions. If Firm $i(i=1,2)$ is a monopolist and enters at time $\mathrm{t}$, its profits are:

$$
\Pi_{i}^{m}(t)=e_{t}^{\infty} e^{-r \tau} \pi_{i}^{m} d \tau-c_{i}(t)
$$

\footnotetext{
${ }^{12}$ We need the following conditions: (1) there is a benefit to introducing the upgrade; (2) there is a benefit to introducing the upgrade when the other firm has done so; and (3) the incremental revenues from being first exceeds the incremental revenue when Firm 1 is the follower.
} 
If Firm 2 enters at time $t_{L}$ followed by Firm 1 at time $t_{F}$, then the expected profits for Firms 2 and 1 are given by:

$$
\begin{aligned}
\Pi_{2}^{L}\left(t_{L}\right) & ={ }_{t_{L}}^{t_{F}} e^{-r \tau} \pi_{2}^{m} d \tau+{ }_{t_{F}}^{\infty} e^{-r \tau} \pi_{2}^{d} d \tau-c_{2}\left(t_{L}\right) \\
& =\frac{\pi_{2}^{m}}{r}\left(e^{-r t_{L}}-e^{-r t_{F}}\right)+\frac{\pi_{2}^{d}}{r} e^{-r t_{F}}-c_{2}\left(t_{L}\right) \\
\Pi_{1}^{F}\left(t_{F}\right) & =e^{\infty} e^{-r \tau} \pi_{1}^{d} d \tau-c_{1}\left(t_{F}\right) \\
& =\frac{\pi_{1}^{d}}{r} e^{-r t_{F}}-c_{1}\left(t_{F}\right)
\end{aligned}
$$

See the Appendix for proofs of strict concavity of the profit functions (Lemma A) and uniqueness of the optimal solutions (Lemma B). We first have the following result (all proofs are in the Appendix).

\section{Lemma 1}

Firm 1's entry time is increasing in $\alpha$.

This lemma shows that as the development costs of Firm 1 increase it would enter later. Consequently, as the development costs of Firm 1 increase, Firm 2 earns monopoly profits for a longer period of time. This implies that Firm 2's profits must be increasing in $\alpha$. Using this observation, we have the following result.

\section{Proposition 1}

Under perfect information about Firm 1's development costs, there exists an $\alpha^{*}$ such that 
Firm 2 enters the market if and only if $\alpha>\alpha^{*}$.

This proposition shows that Firm 2's optimal entry decision depends on its knowledge of Firm 1's product development costs. However, such development cost information is often unavailable to Firm 2 at the time of entry (particularly if Firm 1 has already sunk some resources into product development). Instead, Firm 2 is likely to have only a prior probability distribution of Firm 1's development costs. Consistent with empirical literature on the time-cost relationship (e.g., Putnam and Fitzsimmons 1979), we assume Firm 2 knows $\psi(t)$ but is uncertain of the value of $\alpha$. For simplicity, we assume that $\alpha$ can take two values $\alpha_{\text {low }}$ and $\alpha_{\text {high }}$, where $\alpha_{\text {low }}<\alpha^{*}<\alpha_{\text {high }}$. Firm 2 assigns a probability $\eta$ that Firm 1 has $\alpha=\alpha_{\text {low }}$ (i.e., Firm 1 has relatively low development costs), and probability $1-\eta$ that Firm 1 has $\alpha=\alpha_{\text {high }}$ (i.e., Firm 1 has relatively high development costs). Given the assumption $\alpha_{\text {low }}<\alpha^{*}<\alpha_{\text {high }}$, it follows from Proposition 1 that if Firm 2 has perfect information it will not enter the market if $\alpha=\alpha_{\text {low }}$ and will enter the market if $\alpha=\alpha_{\text {high }}$. Since Firm 2 is not aware of the actual development costs of Firm 1, to make an entry decision Firm 2 must use its prior distribution and possibly Firm 1's preannouncement. Of course, if Firm 2's priors do not favor entry then it does not enter the market. We consider instead the more interesting case where Firm 2's priors favor entry. For 
ease of exposition, we assume that Firm 1 is aware of Firm 2's development $\operatorname{costs}^{13}$.

The next proposition shows that in such situations, preannouncements can serve a useful

purpose. To achieve uniqueness, we restrict beliefs based on the intuitive criterion (Cho and

Kreps $1987{ }^{14}$. We also make the reasonable assumption that firms weakly prefer to

preannounce truthfully. In other words, if a firm is indifferent between preannouncing truthfully

and lying, it prefers to preannounce truthfully.

\section{Proposition 2}

(a) Assume that preannouncing an entry time $T_{a}=0$ is not profitable (this holds for sufficiently large $\alpha_{\text {low }}, \alpha_{\text {high }}$ and $\beta$ ). Then, there exists a unique Perfect Bayesian separating equilibrium in which:

(i) Firm 2's beliefs are:

$$
\operatorname{Pr}\left(\alpha=\alpha_{\text {low }}\right)= \begin{cases}1 & \text { if } T_{a} \leq T_{a}^{*} \\ 0 & \text { otherwise }\end{cases}
$$

i.e., if Firm 1 preannounces a time less than or equal to $T_{a}^{*}$, then Firm 2 believes with certainty that the preannouncement came from a low cost firm.

\footnotetext{
${ }^{13}$ The assumption that the dominant firm knows the development costs of Firm 2 is not critical to our results discussed here. To see this, consider the case when the costs of Firm 2 are modeled as $c_{2}(t)=\theta \varphi(t)$, where $\theta$ is not known by Firm 1 with certainty. Then, $\alpha^{*}(\theta)$ is the critical value of $\alpha$ in Proposition 1 that depends on Firm 2's development costs. There are three possibilities: (1) if $\alpha^{*}(\theta)<\alpha_{\text {low }}$ then Firm 2 will enter regardless of Firm 1's costs; (2) if $\alpha^{*}(\theta)>\alpha_{\text {high }}$ then Firm 2 will not enter regardless of Firm 1's costs; and (3) if $\alpha_{\text {low }}<\alpha^{*}(\theta)<\alpha_{\text {high }}$ then the analysis and results discussed here remain unchanged. Now, in the general case in which there is some probability that Firm 1 is facing a Firm 2 of each of these three types, the benefit function considered in the Appendix will need to be replaced by an expected benefit function, and the appropriate probabilities and outcomes will be considered. For example, letting $\sigma_{1}, \sigma_{2}, \sigma_{3}$, be the respective probabilities that Firm 1 is facing a Firm 2 of the above three types, the probability that a preannouncement has no effect on Firm 2's entry decision is $\sigma_{1}+\sigma_{2}$. If $\sigma_{3}=1$, then our analysis is as before. However, as long as $\sigma_{3}>0$, the benefit function is still increasing in $\alpha$ and the main results of the paper continue to hold. Thus, adding uncertainty about Firm 2's costs would only complicate the presentation of the analysis and not change our basic results.

${ }^{14}$ The intuitive criterion restricts out of equilibrium beliefs that a firm may have in the following way. Consider a deviation by Firm 1 from the equilibrium strategy. If the deviation cannot increase the profits of one type of firm (say the low cost firm) from the equilibrium profits regardless of the beliefs of Firm 2, then the intuitive criterion requires that Firm 2 must believe with certainty that the deviation did not come from this type of Firm 1. A more formal definition is in Cho and Kreps (1987) who also show how the intuitive criterion can be used to select a unique separating equilibrium in Spence's (1974) job market signaling model.
} 
(ii) The low cost Firm 1 preannounces a time $T_{a}^{* *} \leq T_{a}^{*}$ and the high cost Firm 1 preannounces a time $t^{*}\left(\alpha_{\text {high }}\right)>T_{a}^{*} \geq T_{a}^{* *}$.

(iii) Firm 2 does not enter if Firm 1 preannounces a time $T_{a} \leq T_{a}^{*}$ (i.e., Firm 2 believes Firm 1 has low development costs) and enters otherwise (i.e., Firm 2 believes Firm 1 has high development costs).

Thus, in equilibrium, the low cost Firm 1 preannounces a time $T_{a}^{* *}$ and Firm 2 does not enter the market. In contrast, the high cost Firm 1 preannounces a time $t^{*}\left(\alpha_{\text {high }}\right)>T_{a}^{*} \geq T_{a}^{* *}$ and Firm 2 correctly infers that the preannouncement came from a high cost firm and enters the market.

(b) If entry at time 0 is not profitable for Firm 1, then for a given $\alpha_{\text {low }}$ and $\alpha_{\text {high }}$ there exists a range $(\underline{\beta}, \bar{\beta})$ such that if $\beta \in(\underline{\beta}, \bar{\beta})$ then the low cost Firm 1 enters later than its preannounced time (i.e., it intentionally engages in vaporware) and the high cost Firm 1 enters at its preannounced time $\left(t^{*}\left(\alpha_{\text {high }}\right)\right)$. If $\beta>\bar{\beta}$, then both the low cost and the high cost Firm 1 enter at their preannounced time. If $\beta<\underline{\beta}$, then a separating equilibrium does not exist.

(c) For a given $\beta$, there exists an $\underline{\alpha}$ such that if $\alpha_{\text {low }}<\underline{\alpha}$, then Firm 1 of both types (i.e., low and high cost) enters at its preannounced time. If $\alpha_{\text {low }} \in\left(\underline{\alpha}, \alpha^{*}\right)$, where $\alpha^{*}$ is defined in Proposition 1, then the low cost Firm 1 enters at a later date than preannounced (i.e., it intentionally engages in vaporware), while the high cost Firm 1 enters at the preannounced time.

The general intuition for this proposition is straightforward. Note that in our framework, the only benefit that accrues to a firm through preannouncements is that it can deter entry by preannouncing an early enough time. If a firm successfully deters entry by a preannouncement, it can enter as a monopolist. The time of entry will depend on the preannounced time and the firm's product development costs. We know that low cost firms find it less costly to enter at an earlier date than high cost firms. Since the benefit of deterring entry is negatively affected by the penalty that a firm incurs if it does not enter at its preannounced time, intuitively it follows that the benefit from intentional vaporware is larger for the low cost firm. Thus, a low cost firm can credibly signal its 
costs by announcing a time of entry such that the high cost firm would rather enter as a follower than mimic the low cost firm. This is because the high cost firm incurs costs that exceed the benefit of entering as a monopolist. Thus, the dominant firm with high development costs preannounces truthfully and the dominant firm with low development costs intentionally engages in vaporware.

Proposition 2(b) shows how, for a given $\alpha_{\text {low }}$ and $\alpha_{\text {high }}$, the penalty function affects Firm 1's entry timing relative to its preannouncement. First, note that if the penalty for lying is too small then preannouncements are not credible and there is no separating equilibrium. However, as the penalty function reaches a critical value, the low cost firm can credibly signal its development costs by preannouncing. However, for moderate penalty levels the low cost firm finds it profitable to enter at a later date than the date that it preannounced. This is because, after successfully deterring entry, the low cost firm would prefer to enter at a time that maximizes its monopoly profits. Thus, for moderate values of $\beta$ the low cost firm finds it profitable to incur the penalties associated with missing its preannounced time. As the penalty associated with lying increases however, the firm finds it preferable to enter at its preannounced time. Proposition 2(c) shows that a firm with very low costs (i.e., a sufficiently small development cost parameter $\alpha$ ) will enter at its preannounced time. This result is intuitive: if the firm has sufficiently low costs such that it can deter entry by preannouncing its monopoly entry time, then it has no reason to lie. Thus, this proposition implies that the firms that practice intentional vaporware are those with low, but not very low, product development costs.

Finally, our analysis indicates that total expected duopoly profits are higher with preannouncements than without. Given that the dominant firm preannounces its introduction time, the rival firm can save its development expenses by not entering if its competitor has low costs. On 
the other hand, if the dominant firm does not make a preannouncement then the rival firm will enter and lose its investment (with prior probability $\eta$ ) if its competitor has low development costs. With a preannouncement by a dominant firm that has high development costs, the rival firm will earn profits as given by (2). However, if there is no preannouncement then the rival firm only has a $(1-\eta)$ prior probability of earning these same profits.

\section{DISCUSSION}

In this section, we revisit the software industry data to see if there is any empirical evidence that is consistent with our analytical findings in Proposition 2. Unfortunately, detailed cost information at the product development project level is not publicly available. Appropriate information on new product sales and $R \& D$ expenses at the firm level is also not generally available for the firms in our sample. Thus, we follow industry practice and use a productivity measure, i.e., a ratio of sales revenues to the number of employees. We recognize that productivity is a crude measure of product development costs, but it is consistent with the metrics used by firms to assess product development performance (e.g., see McGrath and Romeri 1994; Reinertsen 1997). Moreover, these data are available for several firms in our sample. Finally, to alleviate any concerns over the direction of causality, we use a measure lagged relative to the announcement date.

Using historical data published by $\underline{\text { Soft-Letter and Hoover's Guide to Computer Companies }}$ (1995), this ratio was available for 82 observations in our sample. To allow comparisons at different points in time, we use a measure of relative productivity. This measure was constructed by dividing the firm's productivity by an industry average based on the sales per employee of the top 100 
software companies as reported in Soft-Letter's annual rankings $\underline{\text { S. }}$. Using this approach, we note that over $60 \%$ of the observations in our sub-sample are product announcements by firms with productivity greater than the industry mean $\frac{16}{16}$. The distribution of this measure is shown in Figure 2.

[insert Figure 2 about here]

Since our analytical results in Propositions 2(a) and 2(c) suggest an inverse U-shaped relationship between $\mathbf{V}$ and development costs, we regressed $\mathbf{V}$ on linear and quadratic terms of lagged relative sales per employee, C. The regression model reported below is statistically significant overall

$$
\begin{aligned}
& \mathbf{V}=-1.07+8.06 \mathbf{C}-2.96 \mathbf{C}^{2} \\
& (-0.67) \quad(2.76) \quad(-2.33)
\end{aligned}
$$

$\left(\mathrm{F}(3,82)=4.24, \mathrm{p}=0.02 ; \mathrm{R}^{2}=0.10\right)$. The linear and quadratic terms are significant at better than the 0.05 level (t-ratios in parentheses) ${ }^{1}$. The positive coefficient for $\mathbf{C}$ and the negative coefficient for $\mathbf{C}^{2}$ suggest that an inverted-U shaped relationship exists between productivity and vaporware. We also find that $\mathbf{V}$ is significantly and negatively related to firm size (e.g., relative sales: $r=-0.23$; $p=0.05$, or relative number of employees: $r=-0.24 ; p=0.05$ ). Given that larger firms such as IBM

\footnotetext{
${ }^{15}$ The Soft-Letter 100, published annually since 1984, is a ranking of the top 100 personal computer software companies in the US, based on annual revenues. This list, which includes public and private firms, is based on data directly provided by firms. To insure accountability, estimates from analysts or other outside sources are not used. We thank Jeffrey Tarter, the editor and publisher of Soft-Letter, for making all the historical Soft-Letter 100 rankings between 1984 and 1995 available to us.

${ }^{16}$ Not surprisingly, Microsoft is generally considered to have low product development costs, and in some years very low development costs, using this measure. This is consistent with published information about Microsoft's software development process (Cusumano and Selby 1995).

${ }^{17}$ We note that these results are unchanged when also controlling for firm sales, how far in advance of the release date the announcement was made, whether the firm was publicly or privately owned, and year in which the product announcement was made.
} 
and Microsoft are more likely than smaller firms to attract the attention of antitrust investigators (e.g., Dratler 1996), this result is not surprising since it indicates that larger firms (with greater chance of scrutiny and possible penalty costs) tend to be more accurate in their preannouncements (which is consistent with Proposition 2(b)). These results suggest that, as product development costs increase, $\mathbf{V}$ initially increases, but eventually as product development costs increase sufficiently, $\mathbf{V}$ decreases. Recognizing the limited data that are available to study vaporware, these empirical findings are in agreement with our analytical results in Proposition 2.

\section{IMPLICATIONS AND CONCLUSIONS}

Many industries, including computer hardware and software, have a long history of making announcements in advance of a new product introduction. Certainly there are valid marketing reasons for this practice; yet, preannouncements also afford firms the opportunity to intentionally mislead the market to obtain a competitive advantage. For example, our data suggest that some software firms may have practiced intentional vaporware. Not surprisingly, the possible predatory and anti-competitive implications of false product announcements has caught the attention of the Justice Department.

Consistent with the observed software industry environment, in this paper we consider several important aspects associated with the possible effects of vaporware not previously addressed. First, we study the situation in which intentional vaporware by a dominant firm may be used to deter entry by discouraging the development of a competing new product. Second, we explicitly model the product development time-cost tradeoffs for competing firms and consider asymmetries in development costs between rivals. Finally, we explicitly consider the role of penalty costs in a firm's decision to intentionally engage in vaporware. 
We identify one possible incentive for dominant firms to intentionally engage in vaporware. Analyzing a stylized game theoretic model of the product announcement and introduction timing decisions of two competing firms, we find that preannouncing a product can be a way for a dominant firm to signal its product development costs. A dominant firm with low development costs thus deters entry; it can then enter at a later time than originally preannounced earning monopoly profits that exceed any penalty costs. In addition, dominant firms with very low development costs, having also deterred competitive entry, enter at the preannounced time. These theoretical results are consistent with our empirical observations from the software industry.

It is clear that intentional vaporware can also lead to adverse consumer implications (e.g., higher prices, lack of continuous product innovation). The cost effective dominant firm not only exercises its existing market power by making a (possibly) false product announcement and thus deters entry, but also enhances its power by monopolizing the new market. Our analysis suggests that the government's approach to antitrust law enforcement can influence a firm's incentive to intentionally engage in vaporware (see Proposition 2(b)): to eliminate the incentives for false product announcements, the Justice Department should (1) completely ignore such behavior (hopefully destroying the credibility of any false preannouncements) or (2) crack down on this behavior (thus, raising the penalty costs for any false preannouncement $)^{1,}$. However, both true and false product announcements provide useful information that can be strategically used by smaller competitors to determine their optimal product development and entry strategies. For example, when the dominant firm's preannouncement signals that it has low development costs, the smaller firm does not enter

\footnotetext{
${ }^{18}$ We note that the possible actions by the Justice Department do not consider the possible harm to consumers from false announcements. As discussed earlier, lawsuits involving vaporware have involved millions of dollars in damages (e.g., Prentice and Langmore 1994; Carelton, Weisbach, and Weiss 1996).
} 
and thus saves its development expenses. These potential benefits of intentional vaporware, however, need to be carefully balanced with its possibly harmful consequences. This seems to be one rationale for the Justice Department's interpretation of Section 2 of the Sherman Act, 15 U.S.C. 2, i.e., a violation of antitrust laws requires proof that a preannouncement is both knowingly false and has actual or likely market impact. As our analysis shows, false preannouncements by themselves should not automatically be deemed anti-competitive. This is the same position taken by Ordover and Willig (1981), Prentice and Langmore (1994), Prentice (1996), and Dratler (1996). In our model and results, it is this intermediate position on possible penalties which ensures that intentional vaporware will be practiced by some firms.

Although our analytical and empirical results suggest that firms with low costs (but not extremely low costs) tend to engage in vaporware, some of these firms do truthfully preannounce their products. Why? One possible reason for this lies in our proxy measure for product development costs. Recall that the available data are only at the firm level, not for each product. However, there could be considerable variation in product development costs across products within a firm. Another possible reason lies in our modeling approach. Consistent with prior models, we have considered only a single play of the competitive market entry game. However, in a repeated game framework the dominant firm's penalty costs would accumulate if they always made false product announcements (e.g., their reputation would decay). Thus, we conjecture that under some conditions the dominant firm's optimal strategy is mixing true and false announcements (e.g., see Prentice 1996). This is an area for further research.

Given our findings, the general sentiment within the software industry that preannouncing 
products is not too damaging is understandable since useful product development cost information may be obtained. However, careful scrutiny of this practice on a product by product (not company by company) basis is also necessary to prevent the abuse of market power by cost effective dominant firms. This seems to be the current approach of legal teams filing class action lawsuits, as well as the Justice Department $\stackrel{19}{\text {. }}$

\footnotetext{
${ }^{19}$ For example, four recent investigations of Microsoft launched by the Justice Department involved their proposed merger with Intuit (Hill 1995), bundling application software with Windows95 (Brandt 1995), the practice of requiring computer makers who license Windows95 to promise not to bring patent infringement suits (Novak 1995), and Windows95's tendency to disrupt competitor products' Internet links and programs (Sandberg and Hill 1995). See Black and Wylie (1997) for a recent summary of the various antitrust inquiries involving Microsoft.
} 


\section{APPENDIX}

\section{Lemma A:}

The profits functions $\Pi_{1}^{F}(\mathrm{t})$ and $\Pi_{2}^{L}(\mathrm{t})$ are strictly concave.

\section{Proof of Lemma A:}

The second order condition for Firm 2 is:

$$
\frac{\partial^{2} \Pi_{2}^{L}}{\partial t_{L}{ }^{2}}=\pi_{2}^{m} r e^{-r t_{L}}-c_{2}^{\prime \prime}\left(t_{L}\right)
$$

which is less than zero by assumption. For Firm 1, the second order condition is:

$$
\frac{\partial^{2} \Pi_{1}^{F}}{\partial t_{F}{ }^{2}}=\pi_{1}^{d} r e^{-r t_{F}}-c_{1}^{\prime \prime}\left(t_{F}\right)
$$

which is less than zero since $\pi_{i}^{m}>\pi_{i}^{d}$.

\section{Lemma B:}

There exist unique maximizers $t_{F}^{*}, t_{L}^{*}$ that maximize $\Pi_{1}^{F}(\mathrm{t})$ and $\Pi_{2}^{L}(\mathrm{t})$ respectively.

\section{Proof of Lemma B:}

By definition:

$$
\begin{aligned}
& t_{L}^{*}(\alpha)=\underset{t}{\arg \max } \Pi_{2}^{L}(t) \\
& t_{F}^{*}(\alpha)=\underset{t}{\arg \max } \Pi_{1}^{F}(t)
\end{aligned}
$$

From (2) and (3), the first order conditions for the two firms are:

$$
\begin{aligned}
& -\pi_{2}^{m} e^{-r t_{L}^{*}}-c_{2}^{\prime}\left(t_{L}^{*}\right)=0 \\
& -\pi_{1}^{d} e^{-r t_{F}^{*}}-c_{1}^{\prime}\left(t_{F}^{*}\right)=0
\end{aligned}
$$

We first note that $t_{L}^{*} \leq t_{F}^{*}$. Suppose not, then we must have:

$$
-\pi_{2}^{m} e^{-r t_{F}^{*}}-c_{2}^{\prime}\left(t_{F}^{*}\right)>0
$$

Subtracting (A4) from this equation we get:

$$
-\left(\pi_{2}^{m}-\pi_{1}^{d}\right) e^{-r t_{F}^{*}}-\left(c_{2}^{\prime}\left(t_{F}^{*}\right)-c_{1}^{\prime}\left(t_{F}^{*}\right)\right)>0
$$

But this contradicts the assumption in the paper. Thus, we must have $t_{L}^{*} \leq t_{F}^{*}$. Note that 
(A3) when evaluated at $t=0$ is:

$$
\frac{\partial \Pi_{2}^{L}}{\partial t}=-\pi_{2}^{m}-c_{2}^{\prime}(0)>0
$$

where the inequality follows by Assumption 4. Evaluating (A3) as $t \rightarrow \infty$, we get:

$$
\frac{\partial \Pi_{2}^{L}}{\partial t}=\lim _{t \rightarrow \infty}-c_{2}^{\prime}(t)<0
$$

Thus, from the intermediate value theorem there must exist a $t_{L}^{*}$ which satisfies the first order condition. Furthermore, from the concavity of the profit function established in Lemma A this solution must be unique. An analogous argument establishes that there exists a unique $t_{F}^{*}$.

\section{Proof of Lemma 1:}

Applying the implicit function theorem to (A4), we obtain

$$
\frac{\partial t_{F}^{*}}{\partial \alpha}=\frac{\psi^{\prime}\left(t_{F}^{*}\right)}{r \pi_{l}^{d} e^{-r t_{F}^{*}}-\alpha \psi^{\prime \prime}\left(t_{F}^{*}\right)}=\frac{\psi^{\prime}\left(t_{F}^{*}\right)}{\partial^{2} \Pi_{l}^{F} \partial t_{F}^{2}}>0
$$

where the inequality follows since $\psi^{\prime}\left(t_{F}^{*}\right)=-\pi_{1}^{d} e^{-r_{F}^{*}} / \alpha<0$ and $\partial^{2} \Pi_{1}^{F} / \partial^{2} t_{F}^{2}<0$ by concavity.

\section{Proof of Proposition 1:}

Differentiating (2) and using the Envelope Theorem, we obtain:

$$
\frac{\partial \prod_{2}^{L}}{\partial \alpha}=e^{-r r_{F}^{*}}\left(\pi_{2}^{m}-\pi_{2}^{d}\right) \frac{\partial t_{F}^{*}}{\partial \alpha}>0
$$

where the inequality follows using Lemma 1 . We note that as $\alpha \rightarrow \infty, \Pi_{2}^{L}>0$. Consider the situation when $\alpha=-\left(\pi_{1}^{d} e^{-r t_{L}^{*}}\right) / \psi^{\prime}\left(t_{L}^{*}\right)=\hat{\alpha}>0$. In this case, (A4) becomes:

$$
-\pi_{1}^{d} e^{-r r_{F}^{*}}-\pi_{1}^{d} e^{-r t_{L}^{*}} \psi^{\prime}\left(t_{F}^{*}\right) / \psi^{\prime}\left(t_{L}^{*}\right)=0
$$

which reduces to the condition:

$$
e^{-r\left(t_{F}^{*}-t_{L}^{*}\right)}=\frac{\psi^{\prime}\left(t_{F}^{*}\right)}{\psi^{\prime}\left(t_{L}^{*}\right)}
$$

Note that one solution to the above equation is $t_{F}^{*}=t_{L}^{*}$. We first show that this is the only solution. Let $t_{F}^{*}-t_{L}^{*}=\delta$ and define: 


$$
\Omega(\delta)=e^{-r \delta}-\psi^{\prime}\left(t_{L}^{*}+\delta\right) / \psi^{\prime}\left(t_{L}^{*}\right)
$$

Note that:

$$
\Omega^{\prime}(\delta)=-r e^{-r \delta}-\psi^{\prime \prime}\left(t_{L}^{*}+\delta\right) / \psi^{\prime}\left(t_{L}^{*}\right)
$$

Note that the second term in the above equation is positive since $\psi^{\prime}\left(t_{L}^{*}\right)<0$. Using the second order condition for determining $t_{F}^{*}$ we know that:

$$
\psi^{\prime \prime}\left(t_{F}^{*}\right)>\frac{r \pi_{1}^{d} e^{-r t_{F}^{*}}}{\hat{\alpha}}
$$

Substituting this in the equation for $\Omega^{\prime}(\delta)$ we get:

$$
\Omega^{\prime}(\delta)>-r e^{-r \delta}-\frac{r \pi_{1}^{d} e^{-r t_{F}^{*}}}{\hat{\alpha} \psi^{\prime}\left(t_{L}^{*}\right)}=-r e^{-r \delta}-\frac{r \pi_{1}^{d} e^{-r t_{F}^{*}}}{\left(\frac{\left.-\pi_{1}^{d} e^{-r t_{L}^{*}}\right)}{\psi^{\prime}\left(t_{L}^{*}\right)}\right.} \times \frac{1}{\psi^{\prime}\left(t_{L}^{*}\right)}=-r e^{-r \delta}+r e^{-r \delta}=0
$$

where the first equality follows by using the definition of $\hat{\alpha}$. Thus, $\Omega(\delta)$ is monotonically increasing in $\delta$. Using the monotonicity of the $\Omega(\cdot)$ function in $\delta$ and the fact that $\Omega(0)=0$, it follows that $t_{F}^{*}=t_{L}^{*}$ is the unique solution in the case when $\alpha=-\left(\pi_{1}^{d} e^{-r t_{L}^{*}}\right) / \psi^{\prime}\left(t_{L}^{*}\right)=\hat{\alpha}$. The profits of Firm 2 in this case are:

$$
\Pi_{2}^{L}=\frac{\pi_{2}^{d}}{r} e^{-r t_{L}^{*}}-c_{2}\left(t_{L}^{*}\right)<0
$$

From the continuity of $\Pi_{2}^{L}$ in the range $(\hat{\alpha}, \infty)$, the result follows from the intermediate value theorem and the monotonicity of $\Pi_{2}^{L}$ shown in (A6).

\section{Proof of Proposition 2a:}

Given Firm 2's beliefs, if Firm 1 preannounces a time $t \leq T_{a}^{* *}$ it is optimal for Firm 2 not to enter. This is because by definition $T_{a}^{* *} \leq T_{a}^{*}$ and we know that Firm 2's beliefs are such that if Firm 1 preannounces a time $t \leq T_{a}^{*}$ then Firm 2 believes that Firm 1 is a low cost firm. However, if Firm 1 preannounces a time greater than $T_{a}^{*}$ then it is optimal for Firm 2 to enter the market (since in this case Firm 2 believes that Firm 1 has high costs). To prove that the proposed 
solution is a Perfect Bayesian equilibrium, we need to show that the low cost firm will not benefit from mimicking the high cost firm and vice-versa. These are the incentive compatibility conditions for the equilibrium. These conditions ensure that both types will not prefer to deviate and that the beliefs specified in the proposition are consistent with the equilibrium.

We first note that if entry is deterred, Firm 1 earns the higher monopoly profits. However, Firm 1 also incurs penalty costs if it does not enter at its preannounced time. Let Firm 1's development cost parameter be $\alpha$, denote the benefits to Firm 1 from deterring entry by preannouncing a time $t$ as $B(t, \alpha)$. Then, the incentive compatibility conditions require that:

$$
B\left(T_{a}^{* *}, \alpha_{\text {low }}\right) \geq 0 \text { and } B\left(T_{a}^{*}, \alpha_{\text {high }}\right) \leq 0
$$

Note that the first condition ensures that the low cost firm will benefit from preannouncing the time $T_{a}^{* *}$ and that the high cost firm cannot benefit by pretending to be a low cost firm by preannnouncing a time $T_{a}^{*}$ (which would convince Firm 2 that the firm is a low cost firm). If the above condition is satisfied, then neither firm would like to deviate. If the high cost firm deviates and preannounces a time $T_{a}^{*}$, then it earns additional profits $B\left(T_{a}^{*}, \alpha_{\text {high }}\right)$ which are negative; thus the high cost firm has no incentive to deviate and mimic the low cost firm. The low cost firm also does not benefit by mimicking the high cost firm since if it does, Firm 2 enters the market. However, since $B\left(T_{a}^{* *}, \alpha_{\text {low }}\right) \geq 0$, Firm 1 with low cost prefers to deter entry by preannouncing a time $T_{a}^{* *}$. Thus, the above conditions ensure that neither type will wish to deviate from the equilibrium solution. Further, this implies that given Firm 2's beliefs, if (A7) is true then Firm 1's actions will be such that Firm 2's beliefs will be correct in equilibrium.

We will prove that there exist $T_{a}^{*}$ and $T_{a}^{* * *}$ such that the constraints in (A7) are satisfied. To do this, we will need to consider the case when a preannouncement does not deter entry and the case when entry is deterred. First, consider the case when Firm 1 with cost parameter $\alpha$ truthfully preannounces a time and entry is not deterred. In this case, the time that the firm will preannounce will be given by $t^{*}(\alpha)$ which is implicitly defined by the relevant first order condition:

$$
-\pi_{l}^{d} e^{-r t^{*}(\alpha)}-\alpha \psi^{\prime}\left(t^{*}(\alpha)\right)=0
$$


Now, consider the case when entry is deterred if the firm preannounces a time $T_{a}$. In this case, a firm with cost parameter $\alpha$ will enter at time $T^{*}\left(T_{a}, \alpha\right)$ which is implicitly given by:

$$
T^{*}\left(T_{a}, \alpha\right)=\underset{t}{\arg \max }\left(\Pi_{1}^{L}\left(t\left(T_{a}, \alpha\right), \alpha\right)-p\left(t\left(T_{a}, \alpha\right)-T_{a}\right)\right)
$$

where:

$$
\Pi_{1}^{L}\left(t\left(T_{a}, \alpha\right), \alpha\right)={ }_{t}^{\infty} \pi_{1}^{m} e^{-r \tau} d \tau-\alpha \psi(t)
$$

Thus, the benefit for Firm 1 with a cost parameter $\alpha$ from deterring entry is given by:

$$
B\left(T_{a}, \alpha\right)=\max _{t}\left(\Pi_{1}^{L}\left(t\left(T_{a}, \alpha\right), \alpha\right)-p\left(t\left(T_{a}, \alpha\right)-T_{a}\right)\right)-\Pi_{1}^{F}\left(t^{*}(\alpha)\right)
$$

where $t^{*}(\alpha)$ is defined in (A8). Note that $\Pi_{1}^{F}\left(t^{*}(\alpha)\right)$ does not depend on $T_{a}$ since if Firm 1 is going to be the follower, there is no reason for it to lie, i.e., in this case, the preannounced time will equal the actual time of entry. Now we can establish the existence of $T_{a}^{* * *}$ which satisfies (A7). We prove this through a series of claims.

Define:

$$
\hat{t}=\underset{t}{\arg \max }\left(\Pi_{1}^{L}(t, \alpha)\right)
$$

and

$$
\breve{t}=\underset{t \geq T_{a}}{\arg \max }\left(\Pi_{1}^{L}(t, \alpha)-p\left(t-T_{a}\right)\right)
$$

Claim 1: $\Pi_{1}^{L}(t, \alpha)-p\left(t-T_{a}\right)$ is concave for all $t \geq T_{a}$.

Proof: The relevant second order condition is:

$$
\frac{\partial^{2} \Pi_{1}^{L}(t, \alpha)}{\partial t^{2}}-p^{\prime \prime}\left(t-T_{a}\right)=\pi_{1}^{m} r e^{-r t}-c_{1}^{\prime \prime}(t)-p^{\prime \prime}\left(t-T_{a}\right)<0
$$

which completes the proof.

Claim 2: If $\hat{t} \leq T_{a}$ then $T^{*}\left(T_{a}, \alpha\right)=\hat{t}$.

Proof: Consider a $t \neq \hat{t}$ then:

$$
\Pi_{1}^{L}(\hat{t}, \alpha)>\Pi_{1}^{L}(t, \alpha) \geq \Pi_{1}^{L}(t, \alpha)-p\left(t-T_{a}\right)
$$

where the first inequality follows from the optimality and uniqueness of $\hat{t}$ and the second inequality 
follows since $p(\cdot) \geq 0$. Thus, we must have $T^{*}\left(T_{a}, \alpha\right)=\hat{t}$.

Claim 3: If $\hat{t}>T_{a}$ then $T^{*}\left(T_{a}, \alpha\right)=\breve{t}<\hat{t}$. Further, $\breve{t}>T_{a}$.

Proof: Since $\hat{t}$ is not feasible without incurring a penalty and $\Pi_{1}^{L}(t, \alpha)$ is concave in $\alpha$, it follows that the best the firm can do without incurring the penalty is to enter at $T_{a}$. We have:

$$
\left.\frac{\partial \Pi_{1}^{L}}{\partial t}\right|_{t=T_{a}}>0
$$

Since $p^{\prime}(x)>0$ for all $x>0$ and $0<\lim _{t \downarrow_{a}} p^{\prime}\left(t-T_{a}\right)<\infty$, it follows that there exists an $\varepsilon>0$ such that:

$$
\left.\frac{\partial \Pi_{1}^{L}}{\partial t}\right|_{t=T_{a}+\varepsilon}-p^{\prime}(\varepsilon)=0
$$

which implies that $\breve{t}=T_{a}+\varepsilon>T_{a}$. From the definition of $\breve{t}$, it follows that we must have $T^{*}\left(T_{a}, \alpha\right)=\breve{t}$. To complete the proof we need to show that $\breve{t}<\hat{t}$. Note that at $\breve{t}$ we have:

$$
\left.\frac{\partial \Pi_{1}^{L}}{\partial t}\right|_{t=\breve{t}}-p^{\prime}\left(\breve{t}-T_{a}\right)=0
$$

This implies that

$$
\left.\frac{\partial \Pi_{1}^{L}}{\partial t}\right|_{t=\bar{t}}>0
$$

where the inequality follows since $\breve{t}>T_{a}$ and $p^{\prime}(x)>0$ for $x>0$.

Claim 4: If $\hat{t}=T_{a}$ then $T^{*}\left(T_{a}, \alpha\right)=\hat{t}=\breve{t}$.

Proof: The first part follows from Claim 1. To see the second part, note that in this case we have:

$$
\left.\frac{\partial \Pi_{1}^{L}}{\partial t}\right|_{t=T_{a}}=0
$$

But this implies that for all $t>T_{a}$ we must have:

$$
\left.\frac{\partial \Pi_{1}^{L}}{\partial t}\right|_{t}-p^{\prime}\left(t-T_{a}\right)<0
$$

From the Kuhn-Tucker condition it follows that $\breve{t}=T_{a}$. 
Claim 5: $T^{*}\left(T_{a}, \alpha\right)=\min (\hat{t}, \breve{t})$. Further, $T^{*}\left(T_{a}, \alpha\right)$ is continuous in $\alpha$.

Proof: Immediate from Claims 2-4.

Claim 6: $\left.\frac{\partial \Pi_{1}^{L}}{\partial t}\right|_{t=T^{*}\left(T_{a}, \alpha\right)}-p^{\prime}\left(T^{*}\left(T_{a}, \alpha\right)-T_{a}\right) \leq 0$.

Proof: If $T^{*}\left(T_{a}, \alpha\right)=\hat{t}$ then clearly the inequality is satisfied. If $T^{*}\left(T_{a}, \alpha\right)=\breve{t}$, then the inequality is satisfied since the Kuhn-Tucker condition implies that:

$$
\left.\frac{\partial \Pi_{1}^{L}}{\partial t}\right|_{t=\check{t}}-p^{\prime}\left(\breve{t}-T_{a}\right) \leq 0
$$

Claim 7: $T^{*}\left(T_{a}, \alpha\right)<t^{*}(\alpha)$.

Proof: Suppose, contrary to the claim, $T^{*}\left(T_{a}, \alpha\right) \geq t^{*}(\alpha)$. Note that using (A9) it follows that $T^{*}\left(T_{a}, \alpha\right)$ is defined by the first order condition:

$$
-\pi_{1}^{m} e^{-r T^{*}\left(T_{a}, \alpha\right)}-\alpha \psi^{\prime}\left(T^{*}\left(T_{a}, \alpha\right)\right)-p^{\prime}\left(T^{*}\left(T_{a}, \alpha\right)-T_{a}\right)=0
$$

while $t^{*}(\alpha)$ is defined by:

$$
-\pi_{1}^{d} e^{-r t^{*}(\alpha)}-\alpha \psi^{\prime}\left(t^{*}(\alpha)\right)=0
$$

From the concavity of the profit functions, if (A13) is evaluated at $t^{*}(\alpha)$ and if $T^{*}\left(T_{a}, \alpha\right) \geq t^{*}(\alpha)$, then at that point the LHS of (A13) is greater than or equal to 0 . Thus, we must have:

$$
-\pi_{1}^{m} e^{-r t^{*}(\alpha)}-\alpha \psi^{\prime}\left(t^{*}(\alpha)\right)-p^{\prime}\left(t^{*}(\alpha)-T_{a}\right) \geq 0
$$

Subtracting (A14) from (A15), we obtain:

$$
-\left(\pi_{1}^{m}-\pi_{1}^{d}\right) e^{-r_{t}^{*}(\alpha)}-p^{\prime}\left(T_{a}-t^{*}(\alpha)\right) \geq 0
$$

which is impossible since $\pi_{1}^{m}>\pi_{1}^{d}$ and $p^{\prime} \geq 0$. Thus, we must have $T^{*}\left(T_{a}, \alpha\right)<t^{*}(\alpha)$.

Claim 8: $T^{*}\left(T_{a}, \alpha\right)$ is increasing in $\alpha$.

Proof: From Claim 5 we know that $T^{*}\left(T_{a}, \alpha\right)$ is equal to either $\hat{t}$ or $\breve{t}$. First, consider the case when $T^{*}\left(T_{a}, \alpha\right)=\hat{t}$. In this case, applying the implicit function theorem and by noting the concavity of $\Pi_{1}^{L}(t, \alpha)$ in $t$, it follows that: 


$$
\operatorname{sign}\left(\frac{\partial \hat{t}}{\partial \alpha}\right)=\operatorname{sign}\left(-\psi^{\prime}(\hat{t})\right)>0
$$

Similarly, it follows that if $T^{*}\left(T_{a}, \alpha\right)=\breve{t}$ then using the implicit function theorem we have:

$$
\operatorname{sign}\left(\frac{\partial \breve{t}}{\partial \alpha}\right)=\operatorname{sign}\left(-\psi^{\prime}(\breve{t})\right)>0
$$

Claim 9: $B\left(T_{a}, \alpha\right)$ is decreasing in $\alpha$ and therefore $B\left(T_{a}, \alpha_{\text {low }}\right)>B\left(T_{a}, \alpha_{\text {high }}\right)$.

Proof: First, consider the case when $T^{*}\left(T_{a}, \alpha\right)=\hat{t}$. Differentiating (A11) with $\alpha$ and using the first order conditions for optimality of $t\left(T_{a}, \alpha\right)$ and $t^{*}(\alpha)$ (or by directly applying Envelope Theorem), we get:

$$
\frac{\partial B\left(T_{a}, \alpha\right)}{\partial \alpha}=\psi\left(t^{*}(\alpha)\right)-\psi(\hat{t})<0
$$

where the inequality follows from Claim 7 by noting that $\psi^{\prime}<0$. Now consider the case when $T^{*}\left(T_{a}, \alpha\right)=\breve{t}$. Again, using the relevant first order conditions we have:

$$
\frac{\partial B\left(T_{a}, \alpha\right)}{\partial \alpha}=\left(\frac{\partial \Pi_{1}^{L}(\breve{t}, \alpha)}{\partial t}-p^{\prime}\left(\breve{t}-T_{a}\right) \frac{\partial T^{*}\left(T_{a}, \alpha\right)}{\partial \alpha}+\left(\psi\left(t^{*}(\alpha)\right)-\psi(\breve{t})\right)<0\right.
$$

where the inequality follows since the first term of (A17) is negative using Claim 6 and Claim 8 while the second term is negative using Claim 7.

Claim 10: There exists a $T_{a}^{*}$ such that $B\left(T_{a}^{*}, \alpha_{\text {high }}\right) \leq 0$.

Proof: Since by assumption, Firm 1 does not find it profitable to preannounce a time 0, we must have $B(0, \alpha)<0$. Also, note that if $T_{a} \rightarrow \infty$ and if entry is deterred then the firm incurs no penalty costs and therefore:

$$
\lim _{T_{a} \rightarrow \infty} B\left(T_{a}, \alpha\right)>0 \forall \alpha
$$

Thus, from the intermediate value theorem it follows that there exists a preannouncement time for all types of firms such that $B()>$.0 . However, from Claim 9 we know that $B\left(T_{a}, \alpha_{\text {low }}\right)>B\left(T_{a}, \alpha_{\text {high }}\right)$, which implies that there exists a time $T_{a}^{*}$ such that:

$$
T_{a}^{*}=\sup _{T_{a}}\left\{t \mid B\left(T_{a}, \alpha_{\text {low }}\right)>0 \text { and } B\left(T_{a}, \alpha_{\text {high }}\right) \leq 0\right\}
$$


Now we can establish that the proposed equilibrium is a valid Perfect Bayesian equilibrium of the game. Note that from the proof, the low cost firm can credibly deter entry by pre-announcing a time $T_{a}^{*}$. Given $T_{a}^{*}$, the firm enters at a time $T^{*}\left(T_{a}^{*}, \alpha\right)$ that is defined in Claim 5. Note that if $T^{*}\left(T_{a}^{*}, \alpha\right)<T_{a}^{*}$ then the firm can deter entry by preannouncing its true entry time. Also, from Claim 2 we know that in this case $T^{*}\left(T_{a}^{*}, \alpha\right)=\hat{t}$. Assuming that the firm weakly prefers to tell the truth even when there are no associated penalties, it follows that in this case the firm will preannounce a time $\hat{t}$. Define:

$$
T_{a}^{* *}=\min \left(T_{a}^{*}, \hat{t}\right)
$$

then clearly at $T_{a}^{* *}$ we must have:

$$
B\left(T_{a}^{* *}, \alpha_{l o w}\right)>0 \text { and } B\left(T_{a}^{* * *}, \alpha_{\text {high }}\right) \leq B\left(T_{a}^{*}, \alpha_{\text {high }}\right) \leq 0
$$

i.e., the incentive compatibility conditions are satisfied. From arguments made at the beginning of the proof, it follows that the proposed equilibrium exists and is a valid Perfect Bayesian equilibrium.

We now establish the uniqueness of the equilibrium. We first note that no separating equilibrium of the game will survive refinements of beliefs based on the intuitive criterion. To see this, suppose there exists a separating equilibrium in which Firm 2's beliefs are:

$$
\operatorname{Pr}\left(\alpha=\alpha_{\text {low }}\right)= \begin{cases}1 & \text { if } T_{a} \leq t \\ 0 & \text { otherwise }\end{cases}
$$

Clearly, for the equilibrium to be valid we must have $t \leq T_{a}^{*}$. Consider the case when $t<T_{a}^{*}$. Suppose the low cost Firm 1 deviates and pre-announces a time $T_{a}^{*}$. The solution would require that Firm 2 believe that this preannouncement came from a high cost firm with some probability. However, from Claims 9 and 10 it follows that $B\left(T_{a}^{*}, \alpha_{\text {low }}\right)>0$ while $B\left(T_{a}^{*}, \alpha_{\text {high }}\right) \leq 0$. In other words, preannouncing the time $T_{a}^{*}$ is dominated for the high cost firm by the strategy of truthful preannouncement while it is not for the low cost firm. Thus, if we restrict beliefs based on the intuitive criterion then Firm 2 must believe that a deviation $T_{a}^{*}$ came from a low cost firm and 
we therefore must have $t=T_{a}^{*}$. Thus, the only separating equilibrium that will survive the refinement criterion will be the separating equilibrium specified in the Proposition.

Now we show that no pooling equilibrium of the game survives the refinement criterion. Suppose that there exists a pooling equilibrium of the game. In this case, Firm 2 ignores the preannouncements of Firm 1 and enters the market (since its priors favor entry). Suppose the low cost firm deviates and preannounces a time $T_{a}^{* * *}$. For the pooling equilibrium to survive, Firm 2 must believe that there is some probability that the preannouncement was made by a high cost firm. However, from previous arguments we know that for the high cost firm preannouncing $T_{a}^{* *}$ is dominated by the strategy of announcing truthfully. Thus, it follows that if there is such a deviation, Firm 2 must believe that the deviation came from the low cost firm. This, however, eliminates the pooling equilibrium. Using the same logic, it immediately follows that no hybrid equilibrium of the game survives the criterion of eliminating beliefs based on the intuitive criterion. Thus, the unique equilibrium of the game is the separating equilibrium specified in the Proposition.

\section{Proof of Proposition 2b:}

We prove the proposition through a series of claims.

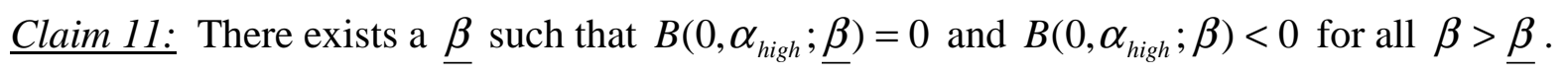
Proof: Note that at $\beta=0$ we have:

$$
B(0, \alpha ; \beta)=\Pi_{1}^{L}(t(0, \alpha), \alpha)-\Pi_{1}^{F}\left(t^{*}(\alpha)\right)>0
$$

Note that $\Pi_{1}^{L}(0, \alpha)<0$. Thus, as $\beta \rightarrow \infty$ :

$$
B(0, \alpha ; \beta)=\Pi_{1}^{L}(t(0, \alpha), \alpha)-\beta \xi^{\prime}(t(0, \alpha))-\Pi_{1}^{F}\left(t^{*}(\alpha)\right)<0
$$

where the inequality is clearly true if $t(0, \alpha)=0$ and for sufficiently large $\beta$ it is true if $t(0, \alpha)>0$. Thus, the existence of $\underline{\beta}$ follows from the intermediate value theorem. To complete the proof we note that using the Envelope Theorem we have:

$$
\frac{\partial B(0, \alpha)}{\partial \beta}=-\xi^{\prime}(t) \leq 0 \text { with strict inequality if } t>0 .
$$

This completes the proof. 
Claim 12: At $\underline{\beta}, T_{a}^{* *}=0$. Furthermore, $T^{*}\left(T_{a}^{* *}, \alpha\right)>0$. In other words, the low cost firm enters at a later time than preannounced.

Proof: First, note that by using Claim 10 we must have the case that at $\underline{\beta}, B\left(0, \alpha_{\text {low }}\right)>0$. Thus, at $\underline{\beta}$ a separating equilibrium clearly exists. From (A18) and the definition of $\underline{\beta}$ in Claim 11 it follows that $T_{a}^{*}=0$. Note that since $\Pi_{1}^{L}(0, \alpha)<0$ we must have $\hat{t}>0$. From (A19) it follows that $T_{a}^{* *}=T_{a}^{*}<\hat{t}$. The result then follows from Claim 3 .

Claim 13: There exists a $\bar{\beta}$ such that $T^{*}\left(T_{a}^{* *}, \alpha_{\text {low }}\right)=T_{a}^{* * *}$ for all $\beta \geq \bar{\beta}$.

Proof: From the definition of $T_{a}^{* *}$ in (A19), it follows that $T^{*}\left(T_{a}^{* *}, \alpha_{\text {low }}\right) \leq \hat{t}$. From Claims 3 and 4 it therefore follows that $T^{*}\left(T_{a}^{* * *}, \alpha_{\text {low }}\right)=\breve{t}$. We first show that for large enough $\beta, \breve{t}=T_{a}^{* * *}$. The relevant Kuhn-Tucker condition is:

$$
\left.\frac{\partial \Pi_{1}^{L}}{\partial t}\right|_{t=\check{t}}-\beta \xi^{\prime}\left(\breve{t}-T_{a}^{* *}\right) \leq 0
$$

Clearly, for sufficiently large $\beta$ (defined as $\bar{\beta}$ ) the equation will be satisfied with strict inequality, which implies that $\breve{t}=T_{a}^{* *}$. To complete the proof, we note that using the implicit function theorem and the concavity of the profit function proved in Claim 1 it follows that:

$$
\operatorname{sign}\left(\frac{\partial \breve{t}}{\partial \beta}\right)=\operatorname{sign}\left(-\xi^{\prime}(\breve{t})\right) \leq 0
$$

Since by definition $\breve{t} \geq T_{a}^{* * *}$ it follows that $\breve{t}=T_{a}^{* * *}$ for all $\beta>\bar{\beta}$.

\section{Proof of Proposition 2c:}

To prove the proposition, we first show that for sufficiently small $\alpha_{\text {low }}$, the firm will preannounce truthfully and that for sufficiently large $\alpha_{\text {low }}$, the firm will enter at a time later than the preannounced time. Recall that:

$$
T_{a}^{* * *}=\min \left(T_{a}^{*}, \hat{t}\right)
$$

The firm preannounces truthfully if $T_{a}^{* * *}=\hat{t}$. Thus, it is sufficient to show that for sufficiently small 
$\alpha_{\text {low }}$, we must have $T_{a}^{*}>\hat{t}$. Clearly, as $\alpha_{\text {low }} \rightarrow 0$ :

$$
\hat{t}=\underset{t}{\arg \max }\left(\Pi_{1}^{L}(t, \alpha)\right)=\underset{t}{\arg \max }\left({ }_{t}^{\infty} e^{-r \tau} \pi_{1}^{m} d \tau-\alpha \psi(t)\right) \rightarrow 0
$$

Since $T_{a}^{*}$ is independent of $\alpha_{\text {low }}$, it follows that for small enough $\alpha_{\text {low }}, T^{*}\left(T_{a}, \alpha\right)=\hat{t}$.

Note that the first order condition for determining $T^{*}\left(T_{a}, \alpha\right)$ is given by:

$$
-\pi_{1}^{m} e^{-r t}-\alpha \psi^{\prime}(t)-p^{\prime}\left(t-T_{a}\right) \leq 0
$$

Since, $\lim _{x \downarrow 0} p^{\prime}(x)<\infty$ and $\psi^{\prime}<0$, it follows that for large enough $\alpha$, (A21) must be satisfied with equality. Thus, we must have the case that for sufficiently large $\alpha, T^{*}\left(T_{a}, \alpha\right)>T_{a}$ i.e., the firm will enter at a date later than the preannounced date. The existence of $\underline{\alpha}$ therefore follows from the intermediate value theorem and the monotonicity of $T^{*}\left(T_{a}, \alpha\right)$ in $\alpha$ that was established in Claim 8. The result follows by noting the condition that $\alpha_{\text {low }}<\alpha^{*}$. 


\section{REFERENCES}

Anderson, C. (1996), “A World Gone Soft: A Survey of the Software Industry,” The Economist, 339 (May 25), S4.

Balachander, S. and K. Srinivasan (1994), "Selection of Product Line Qualities and Prices to Signal Competitive Advantage," Management Science, 40 (7), 824-841.

Black, J. and M. Wylie (1997), "Politics Play into Case," CNet News, August 22, [http://www.news.com/SpecialFeatures].

Blackburn, J., G. Hoedemaker, and L. van Wassenhove (1996), "Concurrent Software Engineering: Prospects and Pitfalls," IEEE Transactions on Engineering Management, 43 (May), 179-188.

Boehm, B.W. (1981), Software Engineering Economics, Englewood Cliffs, NJ: Prentice Hall.

Bowers, B. and U. Gupta (1994), “Shareholder Suits Beset More Small Companies,” Wall Street Journal, March 9, B1.

Brandt, R. (1995), “Still Messin’ With Bill,” Business Week, March 13, 44.

Brooks, F.P. (1975), The Mythical Man-Month: Essays on Software Engineering, Reading, MA: Addison.

Carleton, W. M. Weisbach, and E. Weiss (1996), “Securities Class Action Lawsuits: A Descriptive Study," Arizona Law Review, 38, 491-511.

Carmel, E. and S. Becker (1995), “A Process Model for Software Package Development,” IEEE Transactions on Engineering Management, 42 (February).

Chaney, P., T. Devinney, and R. Winer (1991), "The Impact of New Product Introductions on the Market Value of Firms," Journal of Business, 64(4), 573-610.

Chase, S. (1982), "IBM Has 1.9 Million Boxes of Paper That It Would Love to Toss Away," Wall Street Journal, (June 3), 27.

Cho, I. and D. Kreps (1987) “Signaling Games and Stable Equilibria” Quarterly Journal of Economics, 102 (May), 179-221.

Clark, D. and V. Novak (1995), "Microsoft Savors Major Victory as Pact on Antitrust Is Reinstated by Judges," Wall Street Journal, June 19, A3, A12.

Cusumano, M. (1991), Japan's Software Factories: A Challenge to US Manufacturing, New York: Oxford University Press.

Cusumano, M. and R. Selby (1995), Microsoft Secrets: How the World's Most Powerful Software Company Creates Technology, Shapes Markets, and Manages People, New York: The Free Press.

Dratler, J. (1996), “Microsoft as an Antitrust Target: IBM in Software?” Southwestern University Law Review, 
$25,671-744$.

Dvorak, J. (1993), “Inside Track,” PC Magazine, October 12, 95.

Dyson, E. (1987), “Beware the Hypervapor!” Forbes, July 13, 478.

Eliashberg, J. and T. Robertson (1988), "New Product Preannouncing Behavior: A Market Signaling Study," Journal of Marketing Research, 25, August, 282-292.

Farrell, J. and G. Saloner (1986), "Installed Base and Compatibility: Innovation, Product Preannouncements and Predation," American Economic Review, 76 (5), 940-955.

Flynn, L. (1995), “The Executive Computer,” New York Times, April 24, D4.

Foundyller, C. (1993), “The Preannouncement Quandary,” Computer-Aided Engineering, August, 67.

Fudenberg, D. and J. Tirole (1991), Game Theory, Cambridge, MA: The MIT Press.

Garud, R. (1997), “Betaware's Better than Vaporware,” Journal of Commerce, November 3, 7A.

van Genuchten, M. (1991), "Why is Software Late? An Empirical Study of Reasons for Delay in Software Development," IEEE Transactions on Software Engineering, 17 (June), 582-590.

Graves, S.B. (1989), “The Time-Cost Tradeoff in Research and Development: A Review,” Engineering Costs and Production Economics, 16, 1-9.

Heil, O. and A. Langvardt (1994), "The Interface Between Competitive Market Signaling and Antitrust Law," Journal of Marketing, 58 (July), 81-96.

Heil, O. and T. Robertson (1991), "Towards a Theory of Competitive Market Signaling: A Research Agenda," Strategic Management Journal, 12(6), 403-418.

Hill, G.C. (1995), "Microsoft Drops Bid for Intuit--A Victory for Antitrust Agency," Wall Street Journal, May 22, A1.

Hoover's Guide to Computer Companies (1995), Austin, TX: The Reference Press.

Iansiti, M. and A. MacCormack (1997), "Developing Products on Internet Time," Harvard Business Review, 75 (September-October), 108-117.

Ichbiah, D. (1993), The Making of Microsoft, Rocklin, CA: Prima Publishing.

Jenkins, A. (1988), "Long Overdue: The Reasons Behind Vaporware,” Computerworld, October 5, 11-13.

Johnston, S. (1995), “Vaporware Tactics Elicit Mixed Reviews,” Computerworld, May 1, 1, 147.

Johnston, S. and M. Betts (1995), “Industry Debates U.S. Vaporware Probe,” Computerworld, February 13, 2 . 
Kihlstrom, R. and M. Riordan (1984), “Advertising as a Signal,” Journal of Political Economy, 92, 427-450.

Koku, P., H. Jagpal, and P.V. Viswanath (1997), "The Effect of New Product Announcements and Preannouncements on Stock Price," Journal of Market Focused Management, 2, 183-199.

Landis, R. and R. Rolfe (1985), "Market Conduct Under Section 2 - When is it Anticompetitive?", in F.M. Fisher (ed.), Antitrust and Regulation: Essays in Memory of John J. McGowan, Cambridge, MA: MIT Press, 131-152.

Levy, S. (1997), "Should 'Vaporware' be an Antitrust Concern?” The Antitrust Bulletin, 42 (Spring), 33-43.

Lilly, B. and R. Walters (1997), “Toward a Model of New Product Preannouncement Timing," Journal of Product Innovation Management, 14 (January), 4-20.

Lopatka, J. and W. Page (1995), "Microsoft, Monopolization, and Network Externalities: Some Uses and Abuses of Economic Theory in Antitrust Decision Making," The Antitrust Bulletin, (Summer), 317-370.

Lutz, N. (1989), "Warranties as Signals Under Consumer Moral Hazard," RAND Journal of Economics, 20 (2), 239-255.

Mansfield, E. (1971), Industrial Research and Technological Innovation: An Econometric Analysis, New York: Norton.

McConnell, S. (1996), Rapid Development: Taming Wild Software Schedules, Redmond, WA: Microsoft Press.

McGrath, M. and M. Romeri (1994), "The R\&D Effectiveness Index: A Metric for Product Development Performance," Journal of Product Innovation Management, 11 (June), 213-220.

Milgrom, P. and J. Roberts (1982), “Limit Pricing and Entry Under Incomplete Information,” Econometrica, $50,443-460$.

Moorthy, S. and K. Srinivasan (1995), "Signaling Quality With a Money-Back Guarantee: The Role of Transaction Costs," Marketing Science, 14 (4), 442-466.

Mossberg, W. (1995), "In the Garden They're Bugs; in PCs They're Defects," Wall Street Journal, March 16, B1.

Novak, V. and D. Clark (1995), "Microsoft Antitrust Pact Rejected by Federal Judge," Wall Street Journal, February 15, A3, A9.

Novak, V. (1995), “US Probes Microsoft Licensing Pacts Prohibiting Windows95 Patent Suits,” Wall Street Journal, June 12, B3.

Ordover, J. and R. Willig (1981), “An Economic Definition of Predation: Pricing and Product Innovation,” The Yale Law Journal, 91, 8-53. 
Orrison, A. (1997), “Comment: Response to Article by Stephan M. Levy,” The Antitrust Bulletin, 42 (Spring), 45-49.

Padmanabhan, V., S. Rajiv, and K. Srinivasan (1997), "New Products, Upgrades, and New Releases: A Rationale for Sequential Product Introduction,” Journal of Marketing Research, 34, 456-472.

Papows, J. (1992), “Software Business Practices Improving, But Not Fixed Yet," Computerworld, April 20, 29.

P.C. Letter (1985), April 24, San Mateo, CA.

Porter, M. (1980), Competitive Strategy, New York: The Free Press.

Prentice, R. and J. Langmore (1994), "Beware of Vaporware: Product Hype and the Securities Fraud Liability of High-Tech Companies," Harvard Journal of Law \& Technology, 8 (Fall), 1-74.

Prentice, R. (1996), "Vaporware: Imaginary High-Tech Products and Real Antitrust Liability in a Post-Chicago World," Ohio State Law Journal, 57, 1163-1262.

Putnam, L.H. and A. Fitzsimmons (1979), “Estimating Software Costs,” Datamation, (October), 171-177.

Rabino, S. and T. Moore (1989), "Managing New Product Announcements in the Computer Industry," Industrial Marketing Management, 18, 35-43.

Reinertsen, D. (1997), Managing the Design Factory, New York: The Free Press.

Reinganum, J. (1981), "On the Diffusion of New Technology: A Game Theoretic Approach," Review of Economic Studies, 48, 395-405.

Rigdon, J. (1995), “Frequent Glitches in New Software Bug Users,” Wall Street Journal, January 18, B1, B4.

Robertson, T., J. Eliashberg, and T. Rymon (1995), "New Product Announcement Signals and Incumbent Reactions," Journal of Marketing, 59 (July), 1-15.

Sandberg, J. and G.C. Hill (1995), "Microsoft Probe Spurs Subpoenas Tied to Internet," Wall Street Journal, December 4, A3.

Shapiro, C. and H. Varian (1998), Information Rules: A Strategic Guide to the Network Economy, Boston: Harvard Business School Press.

Shughart, W. (1990), “Private Antitrust Enforcement: Compensation, Deterrence, or Extortion?" Cato Review of Business \& Government, (Fall), 55.

Singh, J. (1997), “The Vaporware Game,” CNet News, April 25, [http://www.news.com/Perspectives].

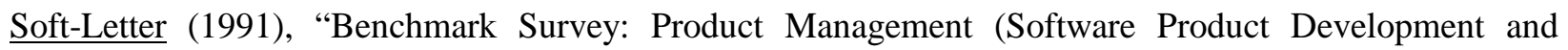
Management: A Survey of 321 Companies)," Cambridge, MA. 
Spence, M. (1974), Market Signaling, Cambridge, MA: Harvard University Press.

Srinivasan, K. (1991), "Multiple Market Entry, Cost Signaling and Entry Deterrence," Management Science, 37 (12), 1539-1555.

U.S. Department of Justice (1995), "Memorandum of the United States of America in Response to the Court's Inquiries Concerning 'Vaporware'," United States v. Microsoft Corporation, Civil Action \#94-1564(SS), January 27.

Wall Street Journal (1982), “The Case That Won't Die,” (April 8), 24.

Wall Street Journal (1996), "Vaporware Tales," comments emailed to the Interactive Edition during the week of November 18-22.

Wind, J. and V. Mahajan (1987), "Marketing Hype: A New Perspective for New Product Research,” Journal of Product Innovation Management, 4, 43-49.

Yoder, S. (1995), “Computer Makers Defend 'Vaporware',” Wall Street Journal, February 16, B1, B6. 
Table 1

Product Announcement Behavior of Software Companies

$(\mathrm{N}=123)$

\begin{tabular}{|c|c|c|c|}
\hline $\begin{array}{c}\text { Time } \\
\text { (months) }\end{array}$ & $\begin{array}{c}\text { Time Between } \\
\text { DATE 1st ANNOUNCED } \\
\text { and } \\
\text { ANNOUNCED RELEASE } \\
\text { DATE }\end{array}$ & $\begin{array}{c}\text { Time Between } \\
\text { ANNOUNCED } \\
\text { RELEASE DATE } \\
\text { and } \\
\text { ACTUAL SHIP DATE } \\
(\mathrm{V})\end{array}$ & $\begin{array}{c}\text { Time Between } \\
\text { DATE 1st ANNOUNCED } \\
\text { and } \\
\text { ACTUAL SHIP DATE }\end{array}$ \\
\hline$<3$ & $18 \%$ & $53 \% *$ & $12 \%$ \\
\hline $3-<6$ & $37 \%$ & $25 \%$ & $28 \%$ \\
\hline $6-<9$ & $15 \%$ & $10 \%$ & $36 \%$ \\
\hline $9-<12$ & $7 \%$ & $6 \%$ & $11 \%$ \\
\hline$>=12$ & $8 \%$ & $6 \%$ & $22 \%$ \\
\hline
\end{tabular}

Source: P.C. Letter's “Official Vapor List” (1985-1995)

*Six cases, or five percent, are negative, i.e., these products were actually introduced before their announced release date. 
Figure 1

Time Between Announced Release Date and Actual Ship Date $(\mathrm{N}=123)$

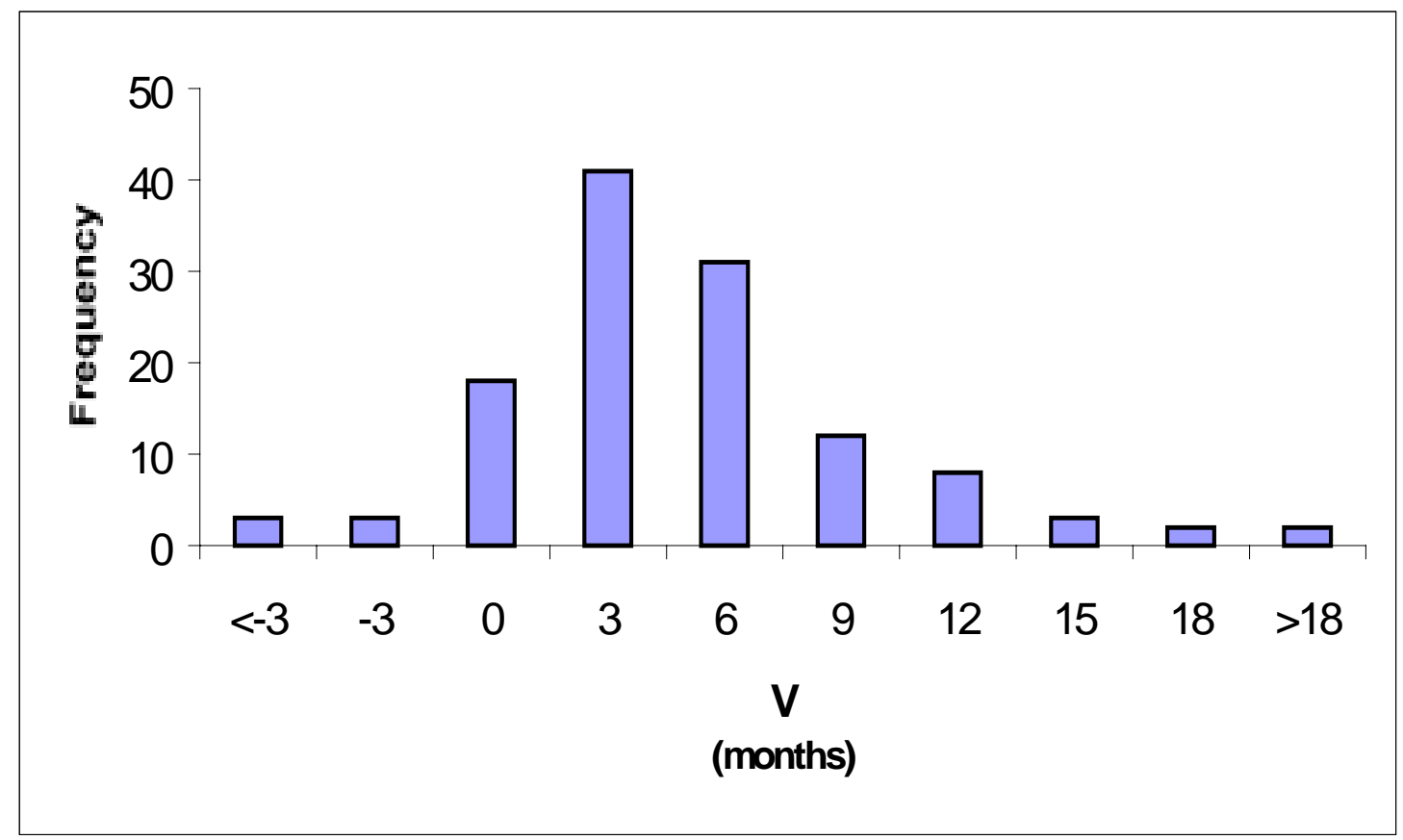


Figure 2

Relative Sales per Employee $(\mathrm{N}=82)$

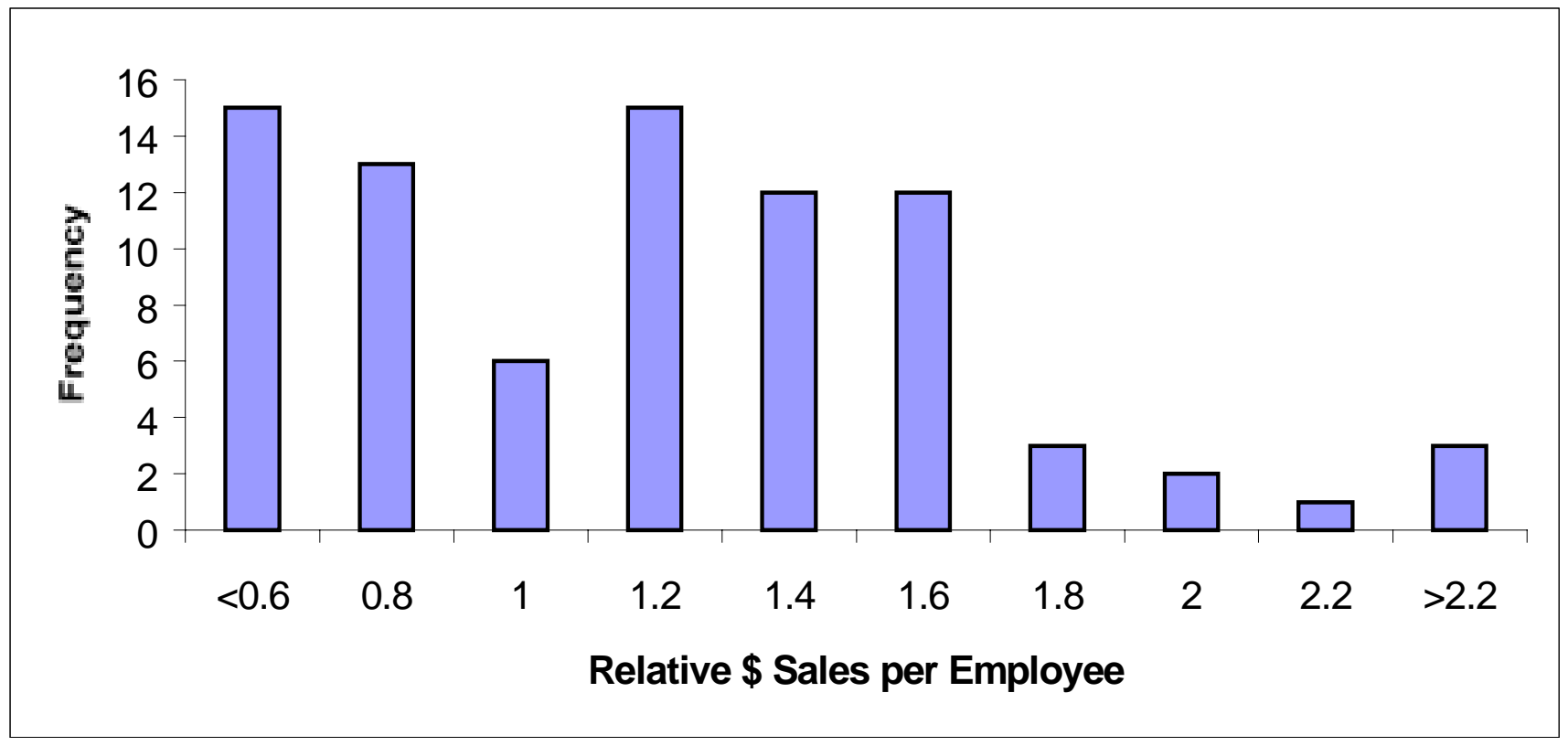

